\title{
Laiduntamisen ja säilörehuniiton aiheuttama ravinne- ja mikrobikuormitus pohjaveteen hietamaalla
}

\author{
Kirsi Järvenranta ${ }^{1}$, Perttu Virkajärvi ${ }^{1}$, Helvi Heinonen-Tanski ${ }^{2}$ ja Irmeli Taipalinen ${ }^{3}$ \\ ${ }^{1}$ Maa- ja elintarviketalouden tutkimuskeskus, Pohjois-Savon tutkimusasema, Halolantie, 71750 \\ Maaninka kirsi.jarvenranta@mtt.fi, perttu.virkajarvi@mtt.fi \\ ${ }^{2}$ Kuopion Yliopisto, Ympäristötieteiden laitos, PL 1627, 70211 Kuopio, helvi.heinonen-tanski@uku.fi \\ ${ }^{3}$ Pohjois-Savon Ympäristökeskus, Sepänkatu 2B, 70100 Kuopio, irmeli.taipalinen@vyh.fi
}

\section{Johdanto}

Laidunten ravinnekuormitus on niittonurmiin verrattuna huomattavasti suurempaa. Niittonurmelta suurin osa annetuista ravinteista poistuu sadon mukana, kun taas laitumilla noin 80 - $90 \%$ lehmän syömistä ravinteista palaa ulosteiden mukana takaisin laitumelle. Ulkomaisten tutkimusten mukaan intensiivisessä laiduntamisessa ulosteiden kohdalle syntyvä typpikuormitus on kerta-annoksena luokkaa $900 \mathrm{~kg} \mathrm{ha}^{-1} \mathrm{ja}$ virtsan vastaava kuormitus 300 - $600 \mathrm{~kg} \mathrm{ha}^{-1}$ (Holmes 1989). Sonnan orgaaninen typpi vapautuu kasveille käyttökelpoiseen muotoon hitaasti, mutta suurin osa virtsan typestä on heti liukoisessa muodossa ja liikkuu helposti maaperää huuhtovan veden mukana pohjavesiin. PohjoisSaksassa tehdyissä tutkimuksissa laitumelta huuhtoutuva nitraatin määrä oli 1.8 -5.0 -kertainen niittonurmiin verrattuna (Benke 1992), mikä johtuu juuri laitumen sisäisestä typpikuormituksesta. Ulosteiden mikrobien huuhtoutuminen pohjavesiin on myös mahdollista. Sen sijaan eritteiden fosfori ei karkeilla kivennäismailla yleensä kulkeudu pohjavesiin saakka, vaan sitoutuu partikkeleihin maan pintakerroksessa.

Tämän tutkimuksen tarkoituksena oli selvittää laitumen ja niittonurmen aiheuttamaa ravinne- ja mikrobikuormitusta pohjavesiin. Erityistä huomiota kiinnitettiin juomapisteen aiheuttamaan kuormitukseen.

\section{Aineisto ja menetelmät}

Koe tehtiin MTT:n Pohjois-Savon tutkimusasemalla Maaningalla sijaitsevalla ympäristökeskuksen lysimetrikentällä. Kentän maaperä on vettä helposti läpäisevää multavaa hietaa. Kokeessa oli kolme laidunruutua, juomapiste ja kuusi niittoruutua (kuva 1). Lysimetrit ovat pinta-alaltaan $100 \mathrm{~m}^{2}$ kokoisia muovikankaasta tehtyjä altaita, joiden sisällä on salaojaputki. Putki johtaa keräysrakennukseen, jossa valumamäärä rekisteröitiin ja vedestä otettiin kokoomanäyte. Näytteestä määritettiin Pohjois-Savon ympäristökeskuksessa $\mathrm{pH}$, sähkönjohtokyky, kokonais-, nitriitti-, nitraatti- ja ammoniumtyppi, kokonais- ja fosfaattifosfori, rauta sekä mangaani. Ainevirtaamat saatiin kertomalla näytteen ainepitoisuudet valumaveden määrällä.

Nurmen alkumassa mitattiin. Lehmien määrä sovitettiin jokaiselle laidunkierrokselle niin, että yhtä eläintä kohti oli tarjolla 23 kg laitumen kuiva-ainetta. Laitumen alku- ja loppukorkeudet mitattiin nurmitikulla. Lisäksi mitattaessa eroteltiin syödyt alueet ja hylkylaikut.

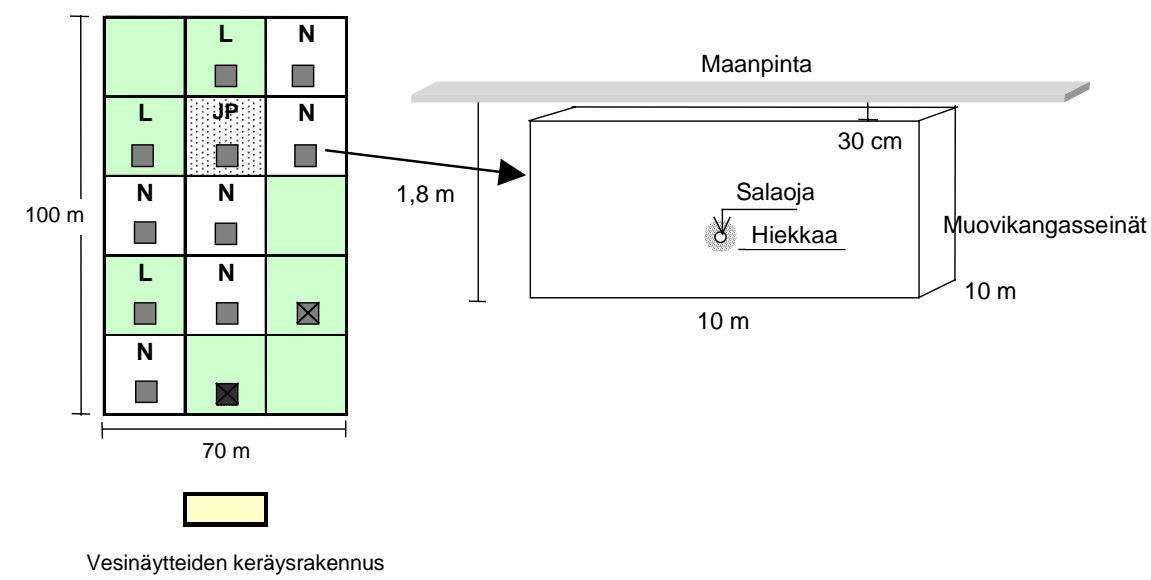

Kuva 1. Kartta lysimetrikentästä ( $N=$ niittoruutu, $L=$ laidunruutu ja JP=juomapiste) sekä lysimetrin rakennekaavio. X:Ilä merkityt lysimetrit eivät olleet käytössä tässä kokeessa. 
Sekä niittonurmen että laidunnurmen lannoitus oli suositusten mukainen $220 \mathrm{~kg} \mathrm{ha}^{-1} \mathrm{a}^{-1}$. Vuonna 1999 laskettiin jokaisen laidunkierroksen jälkeen lysimetriruutujen päälle kertyneet sontakasat, jotta pystyttiin arvioimaan eritteiden mukana laitumelle palautuvien ravinteiden määrä.

\section{Tulokset ja tulosten tarkastelu}

\section{Sadot ja laidunnuksen onnistuminen}

Vuonna 1998 kasvukausi oli sateinen ja viileä, mikä näkyy sadon määrässä verrattuna kuivaan ja lämpimään kesään 1999 (taulukko 1). Säilörehu niitettiin kolmesti ja muu alue laidunnettiin viisi kertaa kesässä. Niittonurmi tuotti molempina vuosina korkeamman yhteiskuiva-ainesadon kuin laidunnurmi. Korkeammasta typpipitoisuudesta johtuen laidunnurmen typpisato oli kuitenkin vuonna 1999 niittonurmen typpisatoa suurempi.

Laiduntaminen onnistui hyvin; laitumen keskimääräiset alku- ja loppukorkeudet vastasivat suositusta kumpanakin vuonna. Hylkylaikkujen (nurmen loppukorkeus $>20 \mathrm{~cm}$ ) osuus oli myös melko alhainen (Virkajärvi ym. 2001). Eläinmäärän mitoitus on ravinteiden huuhtoutumisen kannalta avainasemassa, sillä tulevien ulosteiden määrä on suoraan verrannollinen eläintiheyteen.

Taulukko 1. Sato- ja laidunnustiedot niitto- ja laidunlysimetreiltä 1998-1999. Taulukossa keskiarvot, suluissa keskivirhe.

\begin{tabular}{|c|c|c|c|c|}
\hline & \multicolumn{2}{|c|}{1998} & \multicolumn{2}{|c|}{1999} \\
\hline & Niitto & Laidun & Niitto & Laidun \\
\hline Sato kg KA ha ${ }^{-1}$ & $8810(447)$ & $6020(78)$ & $8980(252)$ & $7940(503)$ \\
\hline $\mathrm{N}$ pitoisuus $\mathrm{g}(\mathrm{kg} \mathrm{KA})^{-1}$ & $26.4(0.28)$ & $36.7(0.54)$ & $27.8(0.62)$ & $34.9(1.05)$ \\
\hline $\mathrm{N}$ sato $\mathrm{kg} \mathrm{ha}^{-1}$ & $233(14.3)$ & $224(6.1)$ & $250(13)$ & $278(26)$ \\
\hline Nautayksikkövuorokausia vuosi $^{-1}$ & & 278 & & 355 \\
\hline Nurmen alkukorkeus, cm (min - maks) & & $16.6-34.7$ & & $14.7-42.0$ \\
\hline Nurmen loppukorkeus, cm (min - maks) & & $9.2-14.4$ & & $7.9-16.0$ \\
\hline Hylkylaikkujen osuus, \% (min - maks) & & $12.0-29.8$ & & $12.0-34.0$ \\
\hline
\end{tabular}

\section{Laitumelle palautuvat ravinteet}

Laitumelle palautuvien ravinteiden määrän arvioimiseksi alueelle kertyvien sontakasojen määrä laskettiin vuonna 1999 jokaisen laidunkierroksen jälkeen. Aarin kokoisen lysimetrin päälle tuli keskimäärin 48 sontakasaa ja juomapisteeseen kasoja kertyi 90 kappaletta. Sontakasojen keskimääräinen paino (2.0 $\mathrm{kg}$ ) saatiin kirjallisuudesta (Haynes ja Williams 1993) ja ravinnepitoisuus rinnakkaisessa laidunkokeessa otetuista sontanäytteistä. Virtsassa erittyvän typen osuus arvioitiin kesällä 1999 asemalla tehdyn fysiologisen kokeen perusteella (MTT, julkaisematon). Virtsassa erittyi arviolta $68 \%$ typestä, mikä on hieman korkeampi kuin Haynesin ja Williamsin (1993) kirjallisuudesta keräämät arvot 60 $65 \%$. Tällä laidunpaineella voidaan siis arvioida laitumelle palautuneen vuonna 1999 typpeä yli $96 \mathrm{~kg}$ ha $^{-1}$ väkilannoituksen lisäksi. Juomapaikan osalta vastaava lisäkuormitus oli n. $181 \mathrm{~kg} \mathrm{ha}^{-1}$.

\section{Huuhtoutuvan veden ravinnepitoisuudet}

Laidun- ja niittoruuduista huuhtoutuvan veden kokonais- ja nitraattityppipitoisuudet olivat vuosina 1998 ja 1999 alhaisia, vaikka nitraattimuodossa oleva typpi liikkuukin vapaasti maaveden mukana (kuva 2). Typpeä huuhtoutui pohjaveteen alle $2 \mathrm{~kg}$ hehtaarilta vuodessa eikä käsittelyiden välillä ollut eroa. Myös kokonais- ja fosfaattifosforipitoisuudet olivat 1998-99 hyvin alhaisia. Fosfori sitoutuu tällä maalajilla pintamaahan eikä huuhtoudu pohjavesiin. Laiduntaminen ei tutkimuksen kahden ensimmäisen vuoden aikana aiheuttanut merkittävää kuormitusta pohjavesiin.

Koko alueen kasvusto tuhottiin glyfosaatilla syksyllä 1999 ja nurmi uusittiin toukokuun lopussa 2000. Koska kasvusto ei enää sitonut ravinteita, laidunlohkoilta tulevan veden nitraattityppipitoisuus kohosi keväällä 2000 huomattavasti (kuva 2) ja juomapaikalta tulevan veden pitoisuus $\left(21,8 \mathrm{mg} \mathrm{l}^{-1}\right)$ ylitti selvästi EU:n nitraattidirektiivin asettaman rajan 11,3 $\mathrm{mg} \mathrm{NO}_{3}-\mathrm{N} \mathrm{l}^{-1}$. Juomapisteestä huuhtoutui nurmen uusimisvuonna $151 \mathrm{~kg}$ kokonais- $\mathrm{N} \mathrm{ha}^{-1} \mathrm{a}^{-1}$ (kuva 3). Valumaveden typpipitoisuus pysyi vuodenajasta riippumatta samana, joten eniten typpeä huuhtoutui keväällä valumahuipun aikana. Nurmen uusimisen on muissakin tutkimuksissa havaittu lisäävän typen mineralisaatiota ja huuhtoutumista eri- 
tyisesti laitumilla, missä maahan kertyy runsaasti sonnan orgaanista typpeä (Johnston ym. 1994; Hassink ym. 1990).

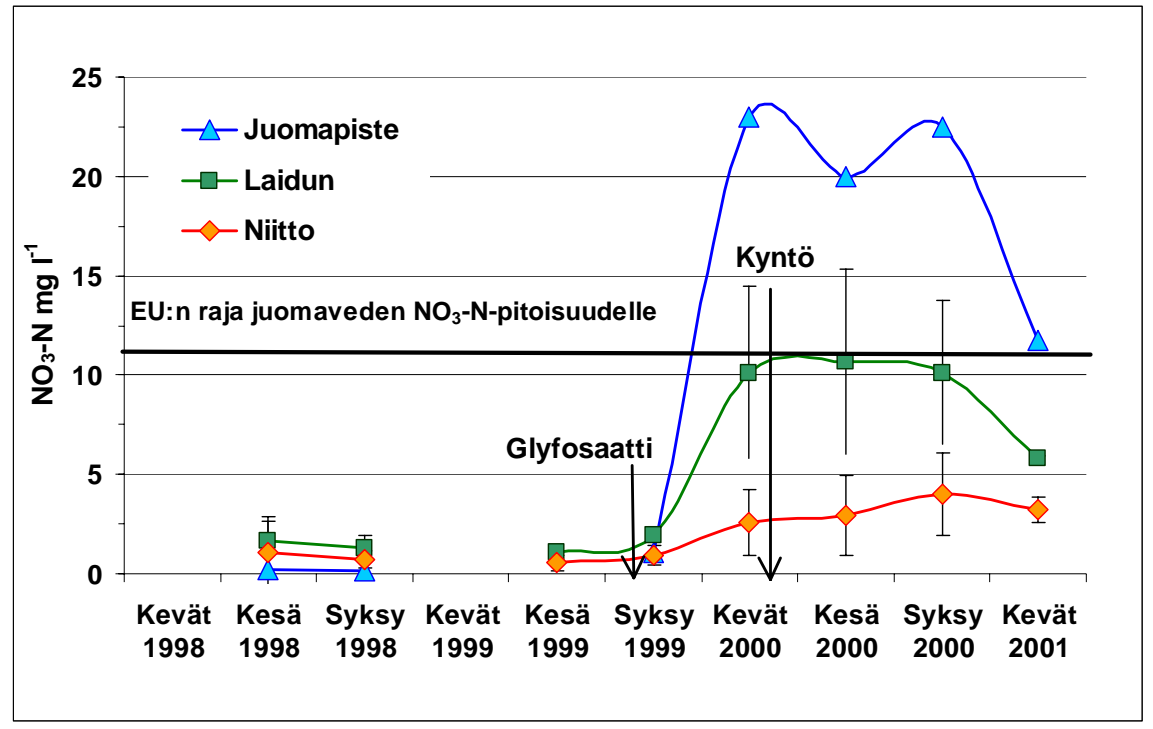

Kuva 2. Niitto- ja laidunlysimetriveden nitraattityppipitoisuus käsittelyvuosina 1998-1999 ja nurmen uusimisvuonna 2000. (Pystyjanat $=$ keskivirhe $)$

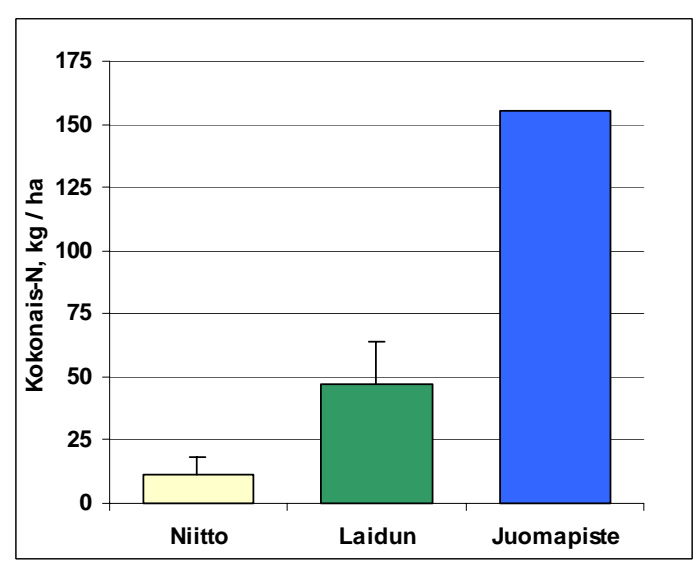

Kuva 3. Niitto- ja laidunlysimetrivedessä huuhtoutunut kokonaistyppimäärä $\left(\mathrm{kg} \mathrm{ha}^{-1}\right)$ nurmen uusimisvuonna 2000. (Pystyjanat $=$ keskivirhe $)$

\section{Niitto- ja laidunalueen typpitase}

Aineiston perusteella laadittiin esimerkinomainen typpitaselaskelma (taulukko 2). Annettuun typpeen laskettiin mukaan lannoitus, väkirehut ja sadeveden mukana tullut typpilaskeuma. Kokeessa ei käytetty lietelantaa nurmea perustettaessa, mikä olisi ollut tavanomainen ratkaisu etenkin niittonurmen osalta. Poistumapuolelle on niittonurmen osalta huomioitu sadon mukana poistunut $\mathrm{N}$, ja huuhtoutunut $\mathrm{N}$. Laidunkoejäsenelle on laskettu maidon mukana poistunut $\mathrm{N}$, lypsyn aikana navettaan eritteissä jäänyt N sekä huuhtoutunut N. Osa eläinten eritteiden typestä myös haihtuu, mutta haihtumista ei ole tutkittu Suomen olosuhteissa, joten sen arvioiminen olisi epävarmaa. Ulkomaisissa tutkimuksissa eritteistä on haihtunut ammoniakin ja typen oksidien mukana 10-30 \% niiden sisältämästä typestä. Koska säilörehun mukana poistuu huomattavasti enemmän typpeä kuin maidossa ja navettaan jääneissä eritteissä, on niittonurmen typpitase negatiivinen ja laitumen positiivinen.

Kahden koevuoden aikana laitumelle kertyi lannoitteissa ja eritteissä yli $380 \mathrm{~kg} \mathrm{~N} \mathrm{ha}^{-1}$.Tästä määrästä poistui nurmen uusimisvuoden sadossa $23,4 \%$ ja huuhtoutui $12,1 \%$. Laitumelle jäi typpeä tämän laskelman mukaan yli $245 \mathrm{~kg} \mathrm{ha}^{-1}$, kun taas niittonurmen typpitase oli kolmen vuoden jälkeen $\mathrm{n}$. $135 \mathrm{~kg} \mathrm{ha}^{-1}$ negatiivinen. Voimakas typen kertyminen selittää sen, että Suomessa tehdyissä laidunten lannoituskokeissa typelle on saatu alhaisia vasteita, (5-10 $\mathrm{kg} \mathrm{ka} \mathrm{kg}^{-1} \mathrm{~N}$, esim. Ettala ym. 1971), kun taas niittonurmilta vastaavissa kokeissa on saatu yli kaksinkertaisia vasteita (esim. Hiivola 1974). Sekä voimakas typen kumuloituminen että lannoituskokeissa lisätypelle saadut alhaiset vasteet viittaavat siihen, että laidunten lannoitusta olisi syytä selvittää tarkemmin. 
Taulukko 2. Niitto- ja laidunalueiden typpitaseet vuosina 1998-2000 (Haihtunutta typpeä ei huomioitu).

\begin{tabular}{|c|c|c|c|c|c|c|}
\hline & \multicolumn{2}{|c|}{1998} & \multicolumn{2}{|c|}{1999} & \multicolumn{2}{|c|}{2000} \\
\hline & Niitto & Laidun & Niitto & Laidun & Niitto & Laidun \\
\hline \multicolumn{7}{|l|}{$\overline{\text { Annettu N kg ha }}^{-1}$} \\
\hline Lannoitus & 220 & 220 & 220 & 220 & - & - \\
\hline Väkirehu & & 26,2 & & 35,8 & & \\
\hline Sadevesi & 2,4 & 2,4 & 2,4 & 2,4 & 2,4 & 2,4 \\
\hline Yhteensä & 222,4 & 248,6 & 222,4 & 258,2 & 2,4 & 2,4 \\
\hline \multicolumn{7}{|l|}{ Poistunut $\mathrm{N} \mathrm{kg} \mathrm{ha}{ }^{-1}$} \\
\hline Säilörehu & 233 & - & 245 & - & $90 *$ & $90 *$ \\
\hline Maito & - & 26,3 & - & 49 & - & - \\
\hline Eritt. lypsyn aikana & & 19,2 & & 26,8 & & \\
\hline Huuhtoutunut & 1,7 & 1,4 & 0,7 & 1,1 & 12 & 46 \\
\hline Yhteensä & 234,7 & 46,9 & 245,7 & 76,9 & 102 & 136 \\
\hline $\mathrm{N}$ tase kg ha ${ }^{-1}$ & $-12,3$ & 201,7 & $-23,3$ & 181,3 & $-99,6$ & $-133,6$ \\
\hline
\end{tabular}

*koko alue niitetty kerralla, ei erillisiä rehunäytteitä laidun ja niittoruuduista

\section{Mikrobit}

Vuonna 1998 saatiin runsaasti vesinäytteitä, koska kesä oli poikkeuksellisen sateinen. Mikrobiologisesti lysimetrivedet eivät - lukuun ottamatta juomapisteenä ollutta ruutua - sisältäneet ollenkaan suolistomikrobeja. Kaikista laidunnuksen aloittamisen jälkeen otetuista juomapisteen vesinäytteistä löydettiin pieni määrä enterokokkeja, mutta ei muita indikaattorimikrobeja, joten kyseessä voisivat olla kasvikunnasta peräisin olevat streptokokit.

Kuivuuden tähden kesältä 1999 saatiin vain vähän näytteitä. Kevään ja kesän näytteistä ei voitu havaita ulosteen mikrobeja. Kokonaismikrobipitoisuudet olivat kohtuullisen pieniä lukuun ottamatta yhden niittoruudun kevään tulosta $160000 \mathrm{kpl} \mathrm{ml}^{-1}$. Syksyllä 1999 maalajiltaan läpäisevimmistä ruuduista tulleiden vesien kokonaismikrobipitoisuudet olivat erittäin korkeita: $13000000-72000000$ $\mathrm{kpl} \mathrm{ml}^{-1}$. Näistä kaksi oli laidunruutuja ja niistä oli osoitettavissa pieniä määriä monia eri ulostemikrobiryhmiä. Myöhemmin samana vuonna saaduista näytteissä ei enää havaittu mitään hälyttävää, paitsi juomapisteen näytteestä löydettiin $1 \mathrm{kpl} \mathrm{ml}^{-1}$ voihappoa tuottava klostridi (joka siis voisi pilata juustonvalmistuksen).

Keväällä 2000 lysimetrivesien heterotrofisten mikrobien geometrinen keskiarvo oli edellisen vuoden niittoruuduista $800 \mathrm{kpl} \mathrm{ml}^{-1}$ ja laidunnusruuduista $4300 \mathrm{kpl} \mathrm{ml}^{-1}$. Ero ei ollut tilastollisesti merkitsevä. Vuoden 1999 juomapaikan lysimetrivesistä ei voitu osoittaa merkkejä ulostesaastunnasta.

\section{Yhteenveto ja johtopäätökset}

Laitumille kertyi kokeen aikana typpeä huomattavasti enemmän kuin niittonurmille. Tämä ei kuitenkaan lisännyt typen huuhtoutumista kahtena ensimmäisenä laidunvuonna niittokäsittelyyn verrattuna. Nurmen uusimisen jälkeisenä vuonna laitumelta huuhtoutui lähes neljä kertaa enemmän typpeä kuin niittoalueelta. Juomapisteestä typpeä huuhtoutui yli $150 \mathrm{~kg} \mathrm{ha}^{-1}$ ja juomapiste on suhteellisesti pahin typpikuormituksen aiheuttaja laitumella. Typen kumuloituminen ja laitumien lannoituskokeissa saadut heikot vasteet annetulle lisätypelle antavat aihetta tarkastaa laitumien lannoitussuosituksia niittonurmiin verrattuna. Lisäksi laiduntaminen ja juomapiste aiheuttavat jonkin verran mikrobikuormitusta pohjavesiin etenkin valumahuippujen aikana.

\section{Lähteet}

Benke, M. 1992. Inauguraldissertation zur Erlangung des Doktorgrades der Agrarwissenschaftlichen Fakultät der Christian-Albrechts-Universitet zu Kiel. 125 p.

Ettala, E., Poutiainen, E., Lampila, M., Rinne, K. \& Takala, M. 1971. Kehittyvä maatalous 4/1971. pp. 18-30. Hassink, J., Scholefield, D. \& Blantern, P. 1990. Proceedings of the $13^{\text {th }}$ General Meeting, European Grassland Federation, Banska Bystrica, Czechoslovakia, Vol. II, pp. 25-32.

Haynes,R.J. \& Williams,P.H. 1993. Nutrient Cycling and Soil Fertility in the Grazed Pasture Ecosystem. Adv. Agron. 49:119-199.

Hiivola, S-L., Huokuna, E., Rinne, S-L. 1974. Agrogeologia et -chimica/Ann. Agric. Fenn 13(70): 149-160.

Holmes, W. 1989. Grass. Its production and utilization. Blackwell Scientific Publications. p. 305

Johnston, A.E., McEwen, J., Lane, P.W., Hewitt, M.V., Poulton, P-R. \& Yeoman, D.P. 1994. J. of Agric. Sci. Cambridge 122:73-89.

Virkajärvi, P., Sairanen, A., Nousiainen, J. \& Järvenranta, K. 2001. Laiduntamisen tehokkuuteen vaikuttavat tekijät. NURMI 2001 Symposium: esitykset ja tilastokuvauksia. Suomen nurmiyhdistyksen julkaisu nro 15:42-47. 